\title{
Investigation on Functional Reserves of the Testosterone-Synthesizing System in the Blood of 12-Month-Old Heifers in Different Breeds
}

\author{
VI Eremenko ${ }^{1}$ and EG Rotmistrovskaya ${ }^{2}$
}

${ }^{1}$ Department of Epizootology, Radiobiology and Pharmacology, I.I. Ivanov Kursk State Agricultural Academy, Kursk, Russia; ${ }^{2}$ Candidate of Biology, Senior Lecturer, AV Zavialov Department of Normal Physiology, Kursk State Medical University, Kursk, Russia

*Corresponding author: eremenko_v.i@kgsha.ru; rotmistrovskaya.lena.@mail.ru

Article History: 20-066 Received: March $15,2020 \quad$ Revised: May 22, 2020 Accepted: June 03,2020
ABSTRA C T
The article presents the data on the functional activity of testosterone-synthesizing system in the 12-month-old black-
and-white Holstein, Simmental, Aberdeen-Angus heifers, as well as cross-bred cows (Simmental x Aberdeen-Angus).
The study had the following goals set: 1 . To compare the data between the experimental groups of heifers of different
breeds. 2 . To carry out the functional stress tests of the testosterone synthesizing system in experimental heifers at the
age of 12 months. 3 . To study the functional activity of the testosterone-synthesizing system in experimental heifers of
different breeds. 4 . To calculate the activity coefficients of the testosterone-synthesizing system in experimental
groups of heifers at the age of 12 months. The studies were carried out on black-and-white Holstein, Simmental, and
Aberdeen-Angus heifers and their crossbred heifers (Simmental x Aberdeen-Angus). In order to determine the
functional reserves of the testosterone synthesizing system, chorionic gonadotropin (CG) was intramuscularly
administered at 12 months of age, and the activity of the testosterone synthesizing system was determined. The
introduction of chorionic hormone at a dose of 0.5 units/kg causes hyperfunction of the testosterone-synthesizing
system. Moreover, the maximum level of testosterone in the blood of heifers at 12 months of age was observed 24
hours after its third administration. The results of the effects of functional stress tests on the testosterone synthesizing
system of the heifers indicate that the potential reserves of the testosterone synthesizing system in the Simmental and
black-and-white breeds at the age of 6 months are lower than in Aberdeen-Angus and cross-breed animals.

Key words: Breeds, Cattle, Functional reserves, Hybrid heifers, Testosterone, Testosterone synthesizing system.

\section{INTRODUCTION}

In recent decades, information has been attracted to this issue that more successful breeding in livestocks requires deeper knowledge in interior indicators, especially about the endocrine system (Crowe et al., 2018). Since testosterone has a pronounced effect on the productive qualities of animals, we therefore set a task to conduct and study the functional loads on the testosterone synthesizing system for heifers of different breeds (Faulkner et al., 1989; Saeid and Zaid, 2019).

Testosterone is a male and female sex hormone (normally it accounts for about $90 \%$ of all secreted androgens) (Rubens and Vermeulen, 1971; Eremenko and Rotmistrovskaya, 2019). The synthesis of testosterone in Leydig cells is regulated by luteinizing hormone (LH) of the anterior pituitary gland. Circulating testosterone in the blood of cattle is $98 \%$ bound to plasma proteins, mainly to globulin, as well as to albumin (Drzhevetskaia, 1994; Marry et al., 1993).
Therefore, changes in the concentration of blood plasma proteins significantly affect the level of free testosterone, which also has biological activity (Misao et al., 1994). In plasma, testosterone decomposes from 50 to 100 minutes (National Center for Biotechnology Information, 2020). A small part of testosterone is converted into estradiol, as it undergoes aromatization. This process is very important for the central nervous system, since these hormones are the basis of the sexual behavior of females and males (Narthan et al., 2001).

In mammals, testosterone derivatives stimulate erythropoiesis (Guo et al., 2015; Patrick et al., 2020) but the main function and effect of testosterone is the anabolic effect; it can accelerate or decelerate the synthesis of enzymes that stimulate protein anabolism (Bhasin et al., 2003; Lam et al., 2017). It also participates in the development of adipose tissue through androgen receptors and significantly increases the breakdown of fats (Bhasin et al., 2003; Lam et al., 2017). There is also evidence that testosterone increases the overall level of homocysteine in

Cite This Article as: Eremenko VI and EG Rotmistrovskaya, 2020. Investigation on functional reserves of the testosterone-synthesizing system in the blood of 12-month-old heifers in different breeds. Int J Vet Sci, 9(3): 425-428. www.ijvets.com (@2020 IJVS. All rights reserved) 
the plasma of females (Giltay et al., 1997). In addition, it takes part in the regulation of many physiological processes through specific receptors, which number can either increase or decrease (Bloom et al., 1992; Fenske, 1996). Through androgen receptors, testosterone inhibits the implementation of the gonadotropin releasing factor gene in the hypothalamus (Cardone et al., 1998), stimulates the implementation of hereditary information of androgen receptors in cells of growing follicles (Franks and Hardy, 2018). An interesting fact is that with stress, the concentration of testosterone in the plasma rises. Moreover, the synthesis of testosterone is stimulated by ACTH (Fenske, 1996).

During puberty in female rats, testosterone lowers insulin uptake and further reduces its degradation (Krakower et al., 1993). The literature provides evidence of a close relationship between the levels of testosterone, progesterone and hormones in the posterior pituitary gland (Nitray et al., 1992). In addition, there is evidence that a decrease in the number of oxytocin receptors during physiological aging in the olfactory bulbs and hypothalamic ventromedial nucleus is associated with a decrease in plasma testosterone levels (Christopher et al., 1997). Also, testosterone affects the synthesis of progesterone in vitro (Tanabe et al., 1992). The above data indicate that testosterone has a multifaceted effect on the development and condition of the body. This influence is not limited to any single period of ontogenesis and any particular period of life. Thus, the problem of studying the hormonal status of cattle of different breeding affiliations and productive qualities is relevant, and the results of its solution will be required by zootechnical and veterinary science and practice. The studies were carried out on black-and-white Holstein, Simmental, and AberdeenAngus heifers and their crossbred heifers (Simmental $\mathrm{x}$ Aberdeen-Angus). In order to determine the functional reserves of the testosterone synthesizing system, chorionic gonadotropin (CG) was intramuscularly administered at 12 months of age, and the activity of the testosterone synthesizing system was determined. This will serve as the basis for the development of tests for early prediction of their future productivity.

\section{MATERIALS AND METHODS}

The objects of study were 12-month-old black-andwhite Holstein, Simmental, and Aberdeen-Angus heifers and crossbreeds of Simmental and Aberdeen-Angus breeds. For the experiment, four groups of animals were formed, 10 animals each. Within each group, the animals were similar in age. Animals were fed according to generally accepted norms that corresponded to their age and physiological state in according to NRC recommendations.

To determine the functional reserves of the testosterone synthesizing system, heifers at the age of 12 months were intramuscularly injected with chorionic gonadotropin (CG) in a dose depending on the live weight of the animal. Such animal studies were carried out at AllRussian Research Institute of Physiology, Biochemistry and Nutrition of farm animals in the neuroendocrine growth regulation laboratory and development of agricultural animals (ethical code: 243).

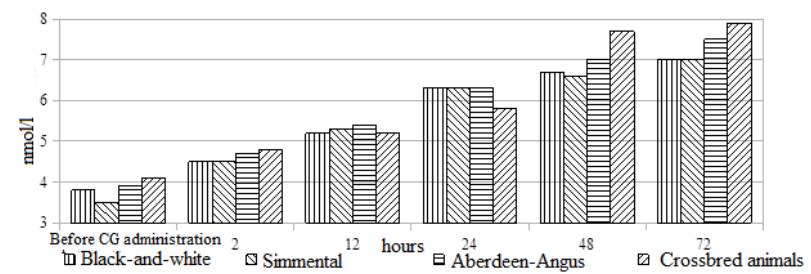

Fig. 1: testosterone-synthesizing system for 12-month-old heifers after administration of CG.

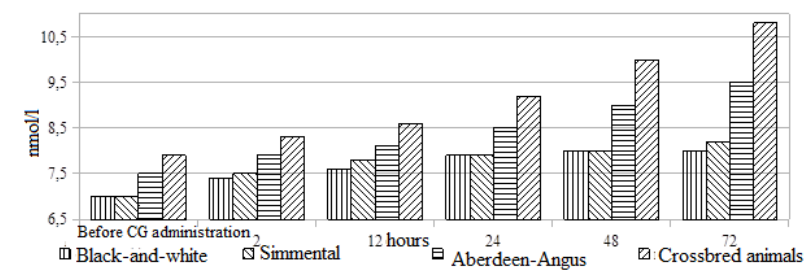

Fig. 2: testosterone-synthesizing system for 12-month-old heifers after second administration of CG.

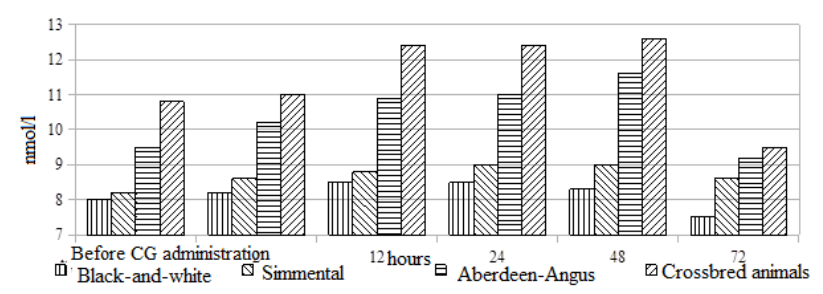

Fig. 3: testosterone-synthesizing system for 12-month-old heifers after third administration of $\mathrm{CG}$.

CG was administered to heifers 3 times with an interval of 72 hours. Blood for testosterone was taken before the introduction of CG and 2, 12, 24, 48, and 72 hours after its administration. The activity index of the testosterone synthesizing system was determined by the formula:

$\mathrm{I}_{\mathrm{tsa}}=\mathrm{T} 1-\mathrm{T} 0 / \mathrm{T} 0$

$\mathrm{I}_{\mathrm{tsa}}$ - testosterone-synthesizing activity index

T0 - basal testosterone level before the first administration of $\mathrm{CG}$.

T1 - testosterone level 24 hours after the third stress test with CG.

\section{RESULTS}

To determine the maximum potential of the testosterone synthesizing system of experimental animals, repeated administration of $\mathrm{CG}$ was carried out. Before the second administration of chorionic gonadotropin, the level of testosterone remained at the same level as 72 hours after the first stimulation.

Following the scheme outlined in "Materials and Methods", CG is to be administered three times. For this, the third administration of chorionic gonadotropin was carried out in experimental heifers at the age of 12 months. Based on the size of the response of the testosterone synthesizing system after the third load, the reserves of the testosterone system were judged. Heifers, whose maximum peak of testosterone was observed after the third functional test, showed higher functional reserves of the testosterone synthesizing system and, accordingly, better adaptive capabilities of the body. 
Int J Vet Sci, 2020, 9(3): 425-428.

Table 1: Dynamics of testosterone in the blood of experimental heifers at 12 months of age after the administration of CG (nmol/L).

\begin{tabular}{|c|c|c|c|}
\hline Breed & Testosterone & acentration & $\mathrm{I}_{\mathrm{tsss}}$ \\
\hline & Basal level (before the first administration) & Maximum level after the third stimulation & \\
\hline Black-and-white Holstein, & 7 & 8.5 & 1.23 \\
\hline Simmental & 7 & 9 & 1.57 \\
\hline Aberdeen-Angus & 7.5 & 11 & 1.97 \\
\hline Crossbred animals & 7.9 & 12.6 & 2.07 \\
\hline
\end{tabular}

Further, using the basal level of the hormone testosterone before the first administration and its maximum concentration after the third stimulation of $\mathrm{CG}$, the activity indices of the testosterone synthesizing system were calculated using the formula described in the Materials and Methods. The obtained calculation data of the activity indices of the testosterone-synthesizing system are shown in Table 1.

\section{DISCUSSION}

The data in Figure 1 show that by the age of 12 months the concentration of this indicator in AberdeenAngus and crossbred heifers was slightly higher than in the group of Black-and-white Holstein and Simmental heifers.

The concentration of testosterone in black-and-white heifers was $3.8 \pm 0.3 \mathrm{nmol} / \mathrm{L}$, in Simmental - 3.5 \pm 0.3 $\mathrm{nmol} / \mathrm{L}$, in Aberdeen-Angus - 3.9 $\pm 0.4 \mathrm{nmol} / \mathrm{L}$, and crossbreed $-4.1 \pm 0.4 \mathrm{nmol} / \mathrm{L}$. There were no statistically significant differences between the experimental groups of heifers during this period $(\mathrm{P}>0.05)$. At the age of 12 months, we performed the first stimulation with CG. After the introduction of CG, the level of testosterone gradually increased. In Eremenko and Rotmistrovskaya (2019), Aberdeen-Angus heifers and cross-breed heifers hade greater functional reserves of the testosterone synthesizing system in compared with Holstein, at the age of 6 months.

The data shown in Figure 1 indicate that 2 hours after the first administration of $\mathrm{CG}$ in the black-and-white heifers the testosterone level was $4.6 \pm 0.4 \mathrm{nmol} / \mathrm{L}$, in the Simmental heifers - $4.5 \pm 0.4 \mathrm{nmol} / \mathrm{L}$, in the AberdeenAngus heifers - $4.8 \pm 0.5 \mathrm{nmol} / \mathrm{L}$; in the crossbred animals $4.8 \pm 0.4 \mathrm{nmol} / \mathrm{L} .12$ hours after the first administration of $\mathrm{CG}$, there was a jump in the level of testosterone in the blood of heifers. In black-and-white Holstein heifers it was up to $5.1 \pm 0.5 \mathrm{nmol} / \mathrm{L}$, in Simmental breed - up to $5.3 \pm 0.5 \mathrm{nmol} / \mathrm{L}$, in Aberdeen-Angus breed - up to 5.2 \pm 0.5 $\mathrm{nmol} / \mathrm{L}$, in crossbreed animals - up to $5.2 \pm 0.5 \mathrm{nmol} / \mathrm{L}$.

The peak concentration of testosterone was detected 72 hours after the first administration of CG: in black-andwhite - 7.0 $\pm 0.4 \mathrm{nmol} / \mathrm{l}$, in Simmental - $7.0 \pm 0.6 \mathrm{nmol} / \mathrm{L}$, in Aberdeen-Angus - $7.5 \pm 0.6 \mathrm{nmol} / \mathrm{L}$ and in crossbreed animals - 7.9 $\pm 0.5 \mathrm{nmol} / \mathrm{L}$.

To determine the maximum potential of the testosterone synthesizing system of experimental animals, repeated administration of CG was carried out. Before the second administration of chorionic gonadotropin, the level of testosterone remained at the same level as 72 hours after the first stimulation.

The highest concentration of hormone in the blood of heifers of both groups was observed 72 hours after the second administration of CG. The concentration of testosterone in black-and-white heifers was $8 \pm 0.5 \mathrm{nmol} / \mathrm{L}$, in Simmental - $8.2 \pm 0.6 \mathrm{nmol} / \mathrm{L}$, in Aberdeen-Angus $9.5 \pm 0.5 \mathrm{nmol} / \mathrm{L}$, and crossbreed - $10.8 \pm 0.7 \mathrm{nmol} / \mathrm{L}$.
Before the third stimulation, the level of testosterone in the blood of experimental animals was slightly higher in crossbred heifers $-10.8 \pm 0.5 \mathrm{nmol} / \mathrm{L}$. The dynamics of changes in testosterone in the blood of 12-month-old heifers after the third administration of CG can be seen in Fig. 3.

After the third administration of $\mathrm{CG}$, the reaction of the testosterone synthesizing system continued to increase, reaching its maximum in all groups after 24 hours. The concentration of testosterone in the blood of 12-month-old heifers after 3 injections of CG after 24 hours was $8.5 \pm 0.4 \mathrm{nmol} / \mathrm{L}$ in black-and-white heifers, in Simmental - 9.0 $\pm 0.4 \mathrm{nmol} / \mathrm{L}$, in Aberdeen-Angus $11.0 \pm 0.8 \mathrm{nmol} / \mathrm{L}$, and crossbreed - $12.4 \pm 1.0 \mathrm{nmol} / \mathrm{L}$. Subsequent administration of CG did not lead to an increase in testosterone in the blood but only maintained the achieved level of the hormone.

The concentration of testosterone after the third injection after 24 hours in the Aberdeen-Angus and crossbreed animals in comparison to the black-and-white heifers was noted as statistically significant $(\mathrm{P}<0.05)$. The concentration of testosterone after the third injection after 24 hours in Symmetal heifers with respect to AberdeenAngus and crossbreed animals was noted as statistically significant $(\mathrm{P}<0.05)$.

After three stimulations, the concentration of testosterone in 12-month-old black-and-white heifers increased 2.3 times, in Simmental -2.5 times, in AberdeenAngus -2.8 times, in crossbreed animals -2.9 times.

The calculation of the activity index of the testosterone synthesizing system in 12-month-old blackand-white heifers was 1.23 , in the Simmental breed -1.57 , in the Aberdeen-Angus breed -1.97, in the crossbreed heifers -2.07 .

Thus, the performed functional stress test showed that the functional reserves of the testosterone synthesizing system in the Aberdeen-Angus heifers and in crossbreed animals have a higher index of activity of the testosterone synthesizing system than the black-and-white and Simmental heifers.

This report is one of initial reports in regard to testosterone function in heifers, and this is completive study for report of Eremenko and Rotmistrovskaya (2019). Whereas breed-related variations in testosterone functional levels is bulls was documented by Post and Bindon (1983) due to study on Brahman cross and Hereford-Shorthorn breeds.

\section{Conclusions}

The introduction of chorionic hormone at a dose of 0.5 units $/ \mathrm{kg}$ causes hyperfunction of the testosteronesynthesizing system. Moreover, the maximum level of testosterone in the blood of heifers at 12 months of age was observed 24 hours after its third administration. The absolute values of blood testosterone in heifers depended 
on their breed. The Aberdeen-Angus and the crossbred Simmental and Aberdeen-Angus heifers had higher responses to the introduction of CG. Relatively lower responses were observed for heifers of the black-andwhite Holstein and Simmental breed. In our opinion, the revealed differences are associated with the genetic characteristics of the studied animal breeds.

\section{REFERENCES}

Bhasin S, Taylor WE and Singh R, 2003. The mechanisms of androgen effects on body composition: mesenchymal pluripotent cell as the target of androgen action. J. Gerontol. A Biol Sci Med Sci, 58(12): M1103-M1110.

Bloom DF, Bloch GJ and Gorski RA, 1992. Effects of thymectomy on reproductive function and behavior. Physiol. Behav, 52: 291-298. Doi: https://doi.org/10.1016/ 0031-9384(92)90274-6.

Cardone A, Angelini F and Varriale B , 1998. Autoregulation of estrogen and androgen receptor messenger rnas and down regulation of androgen receptor messenger RNA by estrogen in primary cultures of Lizard testis cells. Gen. Comp. Endocrinol., 110: 227-236. Doi: https://doi.org/ 10.1006/ gcen.1998.7063.

Christopher JS, David E Kuehl Suzie A, Ferreira G, et al., 1997. Hypothalamic sites of action for testosterone, dihydrotestosterone, and estrogen in the regulation of luteinizing hormone secretion in male sheep. Endocrinology, 138: 3686-3694, https://doi.org/10.1210/ endo.138.9.5401.

Crowe MA, Hostens M and Opsomer G, 2018. Reproductive management in dairy cows - the future. Irish Vet J, 71: 1. doi:10.1186/s13620-017-0112-y.

Drzhevetskaia IA, 1994. Fundamentals of physiology of metabolism and endocrine system. M.: Vysshaia shkola, Russian Press, Moscow, 256 p.

Eremenko VI and Rotmistrovskaya EG, 2019. Functional reserves of the testosterone synthesizing system in the blood of heifers in different breeds. World Vet J, 9(4): 297301. DOI: https://dx.doi.org/10.36380/scil.2019.wvj37.

Faulkner D, Mckeith F, Berger L, et al., 1989. Effect of testosterone propionate on performance and carcass characteristics of heifers and cows. J Anim Sci, 67: 19071915. Doi:10.2527/jas1989.6781907x.

Fenske M, 1996. Dissociation of plasma and urinary steroid values after application of stressors, insulin, vasopressin, acth, or dexamethasone in the mongolian gerbil. Experim. Clin Endocrinol Diabet, 104: 441-446. DOI: $10.1055 / \mathrm{s}-$ 0029-1211482.

Franks S and Hardy K, 2018. Androgen action in the ovary. Front. Endocrinol, 9: 452. Doi: https://doi.org/10.3389/ fendo. 2018.00452.

Giltay EJ, Hoogeveen EK, Elbers JMH, et al., 1998. Effects of sex steroids on plasma total homocysteine levels a study in transsexual males and females. J Clin Endocrinol Met, 83: 550-553. DOI: $10.1210 /$ jcem.83.2.4574

Guo W, Bachman E, Vogel J, et al., 2015. The effects of shortterm and long-term testosterone supplementation on blood viscosity and erythrocyte deformability in healthy adult mice, Endocrinology 156: 1623-1629. Doi: https://doi.org/ 10.1210/en.2014-1784.

Krakower GR, Meier DA and Kissebah AH, 1993. Female sex hormones, perinatal, and peripubertal androgenization on hepatocyte insulin dynamics in rats. Am J Physiol, 264: E342-E347. DOI: 10.1152/ajpendo.1993.264.3.E342

Lam T, Poljak A, McLean M, et al., 2017. Testosterone prevents protein loss via the hepatic urea cycle in human. Eur J Endocrinol, 176(4): 489-496. doi:10.1530/EJE-16-0868.

Marry R, Grenner D, Meyes P, et al., 1993. Human Biochemistry. Trans. from English . Ed. Ginodman LM Mir Publication, Moscow.

Misao R, Itoh N, Mori H, et al., 1994. Sex hormone binding globulin mRNA levels in human uterine endometrium. Euro J Endocrinol, 131: 623-629. DOI: 10.1530/eje.0.1310623.

Nathan L, Shi W, Dinh H, et al., 2001. Testosterone inhibits early atherogenesis by conversion to estradiol: critical role of aromatase. PNAS, 98: 3589-3593. DOI: 10.1073/pnas. 051003698 .

National Center for Biotechnology Information. PubChem Database, 2020. Testosterone, CID $=6013$. Online: https://pubchem.ncbi.nlm.nih.gov/compound/Testosterone (accessed on Feb. 12, 2020).

Nitray J, Sirotkin A and Poltarsky J, 1992. Progesterone and testosterone production in granulosa cells of sow ovaries after invitro nonapeptide hormone administration. Vet Med Praha 37: 371-377. PMID: 1413399.

Post TB and Bindon BM, 1983. Plasma luteinizing hormone and testosterone concentrations in different breeds of young beef bulls in the tropics. Australian J Biol Sci, 36: 545-549. DOI: https://doi.org/10.1071/bi9830545.

Rubens R and Vermeulen A, 1971. Plasma testosterone levels in women in normal and pathological conditions. Euro J Obst. Gynec. 1: 207-218, https://doi.org/10.1016/0028-2243(71) 90022-0.

Saeed FF and Zaid NW, 2019. Serum and testicular testosterone levels of ram lamb during puberty. Adv Anim Vet Sci 7(2): 92-95. DOI: http://dx.doi.org/10.17582/journal.aavs/2019/ 7.2.92.95

Tanabe K, Tamura T, Saijo A, et al., 1992. Modulation of progesterone secretion by androgens in porcine granulosa cell cultures. Horm Res, 1992. 37, N S1. pp: 25-31. Doi: https://doi.org/10.1159/000182342. 